\title{
FAKTOR-FAKTOR YANG MENENTUKAN KEPUASAN PELANGGAN SEPEDA MOTOR MATIC HONDA DI KOTA DENPASAR
}

\author{
Ni Kadek Lestari Putri ${ }^{\S 1}$, Ni Made Asih ${ }^{2}$, Desak Putu Eka Nilakusmawati ${ }^{3}$ \\ ${ }^{1}$ Jurusan Matematika, Fakultas MIPA - Universitas Udayana [Email: lestariputri1068@yahoo.com] \\ 2Jurusan Matematika, Fakultas MIPA - Universitas Udayana [Email: asihmath77@gmail.com] \\ ${ }^{3}$ Jurusan Matematika, Fakultas MIPA - Universitas Udayana [Email:nilakusmawati_desak@yahoo.com] \\ ${ }^{\S}$ Corresponding Author
}

\begin{abstract}
This study aimed to elaborate the dominant factor affecting consumer's loyalties regarding Honda motor matic and to determine effective marketing strategy for this product. This study conducted at Denpasar where 150 respondents randomly chosen as the data sources. From factor analysis, we found emotional factor is the most dominant factor for consumer's loyalties with eigen value as much as 3,365 and variance explained by this factor is 48,08 percent. Meanwhile, to determine effective marketing strategy, we found the product's quality dominated by its design; service quality dominated by service reliability, emotional factor dominated by the product's esthetic, each of these has communalities as much as 56,38 percent; 72,33 percent, and 65,20 percent respectively.
\end{abstract}

Keywords: Dominant factor, Factor analysis, Honda motor matic, Marketing strategy.

\section{PENDAHULUAN}

Salah satu transportasi darat yang merupakan kendaraan bermotor dari kelas paling minim adalah sepeda motor. Sepeda motor diminati oleh orang-orang karena harganya terjangkau, irit, perawatan mudah, suku cadang ada dimana-mana, tidak mengambil banyak tempat untuk parkir, pemakaiannya praktis, dan mengurangi waktu yang diperlukan seseorang apabila akan melakukan perpindahan dari suatu tempat ke tempat lainnya. Dari alasan tersebut pertumbuhan pengguna sepeda motor semakin meningkat setiap tahun.

Menurut data dari Asosiasi Industri Sepeda motor Indonesia (AISI) tercatat tahun 2014, total penjualan sepeda motor dari Januari sampai Juni sebesar 4.216.473 unit, dengan penjualan motor matic sebesar 2.711 .603 unit $(64,31 \%)$, motor bebek sebesar 916.313 unit $(21,73 \%)$, dan motor sport sebesar 588.577 unit $(13,96 \%)$. Dari total penjualan tersebut, sepeda motor Honda mencapai penjualan tertinggi yaitu $63,35 \%$, dengan penjualan motor matic Honda 1.876.789 unit, motor bebek Honda 513.465 unit dan motor sport Honda 238.874 unit. Sehingga sepeda motor matic Honda unggul dari produk lainnya.

Keunggulan suatu produk menghasilkan kepuasan bagi pelanggan. Kepuasan pelanggan yaitu tingkatan dimana anggapan kinerja (perceived performance) produk akan sesuai dengan harapan seorang pelanggan (Kotler [1]). Kepuasan pelanggan dipengaruhi oleh beberapa faktor yang terbagi oleh dimensi diantaranya:

1. Kualitas produk; Kemampuan suatu produk untuk melaksanakan fungsinya meliputi, daya tahan keandalan, ketepatan kemudahan operasi dan perbaikan, serta atribut bernilai lainnya. Kualitas produk terdiri dari enam dimensi yaitu performance, reliability, fitur, durability, conformance, dan design.

2. Harga; Jumlah uang yang dibutuhkan untuk mendapatkan sejumlah kombinasi dari barang serta pelayanannya. 
3. Service quality; Suatu persepsi tentang revolusi kualitas secara menyeluruh yang terpikirkan dan menjadi suatu gagasan yang harus dirumuskan (formulasi) agar penerapannya (implementasi) dapat diuji kembali (evaluasi), untuk menjadi suatu proses yang dinamis, berlangsung, terus menerus dalam memenuhi kepuasan pelanggan. Dimensi yang terdapat dalam service quality adalah tangible, reliability, responsiveness, assurance, dan emphaty.

4. Emotional factor; Diperoleh dari pelanggan yang merasa puas setelah melalui serangkaian evaluasi yang sebagian bersifat rasional dan emosional. Emotional factor terdiri dari tiga dimensi diantaranya estetika, self expressive value, brand personality.

5. Kemudahan; dimana kemudahan yang dimaksud dalam penelitian ini, untuk mendapatkan produk atau jasa tersebut. Pelanggan akan semakin puas apabila relatif mudah, nyaman dan efisien dalam mendapatkan produk atau pelayanan.

Terdapat empat indikator kepuasan pelanggan, diantaranya perasaan puas, selalu membeli produk, akan merekomendasikan kepada orang lain, dan terpenuhinya harapan pelanggan setelah membeli produk (Irawan [2]). Adapun tujuan dari penelitian ini adalah mengetahui faktor dominan yang berpengaruh terhadap loyalitas pelanggan sepeda motor matic Honda dan menentukan strategi pemasaran yang efektif terhadap produk sepeda motor matic Honda di Kota Denpasar.

Analisis faktor merupakan suatu teknik analisis yang digunakan untuk memberikan pemahaman yang mendasari dimensi-dimensi suatu kasus. Kegunaan analisis faktor yaitu untuk mengurangi jumlah data atau dengan kata lain, melakukan peringkasan sejumlah variabel (Sarwono [3]). Prinsip dasar pada analisis faktor yaitu dengan mengekstrasi sejumlah faktor dari gugusan variabel asal $X_{1}, X_{2}, \ldots, X_{P}$ sehingga banyaknya faktor lebih sedikit dari banyaknya variabel asal $X$ dan sebagian besar informasi (ragam) variabel asal $X$ tersimpan dalam faktor. Tujuan utamanya adalah menentukan struktur yang mendasari korelasi antar sejumlah variabel (Jhonson \& Wichern [4]). Analisis faktor memiliki Analisis Komponen Utama (AKU) yang mempunyai arti suatu teknik analisis untuk mentransformasi variabel-variabel asli yang masih berkorelasi satu dengan yang lain menjadi satu set variabel baru yang tidak berkorelasi lagi. AKU mempunyai banyak kemiripan, yaitu proses komputasi pada analisis faktor didekati dengan solusi AKU. Model umum dari analisis faktor sebagai berikut (Jhonson \& Wichern [4]):

$$
\begin{aligned}
& X_{1}-\mu_{1}=l_{11} F_{1}+l_{12} F_{2}+\cdots+l_{1 m} F_{m}+\varepsilon_{1} \\
& X_{2}-\mu_{2}=l_{21} F_{1}+l_{22} F_{2}+\cdots+l_{21 m} F_{m}+\varepsilon_{2} \\
& \quad \vdots \\
& X_{p}-\mu_{p}=l_{p 1} F_{1}+l_{p 2} F_{2}+\cdots+l_{p m} F_{m}+\varepsilon_{p}
\end{aligned}
$$

Model analisis faktor dapat dinyatakan dalam bentuk matriks sebagai berikut:

$$
\begin{aligned}
& X_{(P \times 1)}-\mu_{(p \times 1)}=l_{(p \times m)} F_{(m \times 1)}+\varepsilon_{(p \times 1)} \\
& {\left[\begin{array}{c}
X_{1}-\mu_{1} \\
X_{2}-\mu_{2} \\
X_{3}-\mu_{3} \\
\vdots \\
X_{P}-\mu_{P}
\end{array}\right]_{(P \times 1)}\left[\begin{array}{ccccc}
l_{11} & l_{12} & l_{13} & \cdots & l_{1 m} \\
l_{21} & l_{22} & l_{23} & \cdots & l_{2 m} \\
l_{31} & l_{32} & l_{33} & \cdots & l_{3 m} \\
\vdots & \vdots & \vdots & \vdots & \vdots \\
l_{p 1} & l_{p 2} & l_{p 3} & \cdots & l_{p m}
\end{array}\right]_{(p \times m)}\left[\begin{array}{c}
F_{1} \\
F_{2} \\
F_{3} \\
\vdots \\
F_{m}
\end{array}\right]_{(m \times 1)}\left[\begin{array}{c}
\varepsilon_{1} \\
\varepsilon_{2} \\
\varepsilon_{3} \\
\vdots \\
\varepsilon_{p}
\end{array}\right]_{(p \times 1)}}
\end{aligned}
$$

keterangan :

$X=$ Vektor variabel asal

$l=$ Matriks faktor pembobot

$F \quad=$ Vektor faktor bersama

$\varepsilon \quad=$ Vektor faktor spesifik

$\mu \quad=$ Rata-rata dari vektor $\mathrm{X}$

Ada beberapa hal yang perlu diperhatikan dalam analisis faktor diantaranya:

a. Ragam peubah asal $\mathrm{X}$

Pada analisis faktor ragam peubah asal $\mathrm{X}$ mempunyai dua komponen yaitu komunalitas (communality) dan ragam galat (specific variance) yang mempunyai persamaan sebagai berikut:

$\operatorname{Var}\left(X_{i}\right)=h_{i}^{2}+\boldsymbol{\psi}$

b. Faktor bermakna

Faktor dalam analisis faktor memiliki nilai eigen lebih besar dari satu $(\lambda>1)$ dinyatakan sebagai fakto2r bermakna. 
c. Peranan faktor

Faktor yang bermakna selain menggunakan variabel nilai eigen dan proporsi keragaman komulatif, juga melakukan peranan faktor. Peranan $F_{\mathrm{j}}$ adalah menjelaskan keragaman total data, dinyatakan dengan persamaan sebagai berikut:

$$
\frac{\sum_{i=1}^{p} c_{i j}}{\operatorname{tr}\left(\sum\right)} \times 100 \%
$$

d. Peragam antara $\mathrm{X}$ dan $\mathrm{F}$

Peragam antara $X_{i}$ dan $F_{j}$ dinyatakan persamaan sebagai berikut:

$$
\operatorname{Cov}\left(X_{i}, F_{j}\right)=c_{i j}
$$

e. Rotasi Faktor

Tujuan dari rotasi faktor adalah agar dapat memproleh struktur faktor yang lebih sederhana agar mudah diinterpretasikan. Pada analisis faktor terdapat 2 metode rotasi yang berbeda yaitu orthogonal rotation dan oblique rotation. Orthogonal rotation merupakan metode rotasi yang mengekstraksi faktor dengan cara merotasikan sumbu faktor yang dipertahankan tegak lurus dengan sudut $90^{\circ}$ dengan kata lain memiliki variabel yang baru yang saling bebas (independent). Dan Oblique rotation merupakan metode rotasi yang mengekstrasi faktor yang merotasikan sumbu faktor yang saling membentuk sudut dengan besar sudut tertentu yang menghasilkan variabel-variabel baru yang tidak saling korelasi.

f. Skor/bobot faktor

Skor faktor merupakan ukuran individual pada faktor yang merupakan nilai rata-rata terbobot, dan bobot yang diberikan sesuai dengan besarnya muatan faktor.

g. Pemotongan (cut off) skor faktor yang dirotasi. Pemotongan akan dilakukan didasarkan pada nilai-nilai tertentu pada jumlah sampel. Dapat dilihat pada tabel 1 .
Tabel 1. Pemotongan (cut off)

\begin{tabular}{c|c}
\hline Skor Faktor & $\begin{array}{c}\text { Ukuran sampel } \\
\text { yang dibutuhkan } \\
\text { untuk signifikansi }\end{array}$ \\
\hline 0.30 & 350 \\
0.35 & 250 \\
0.40 & 200 \\
0.45 & 150 \\
0.50 & 120 \\
0.55 & 100 \\
0.60 & 85 \\
0.65 & 70 \\
0.70 & 60 \\
0.75 & 50 \\
\hline
\end{tabular}

Sumber : Hair, et al (1995)

Ada dua tipe yang dimiliki dalam analisis faktor yaitu analisis eksploratif (Exploratory Factor Analysis/EFA) dan analisis konfirmatif (Confirmatory Factor Analysis/CFA). Dua tipe tersebut digunakan dalam penelitian ini, yang akan dijelaskan sebagai berikut:

1. Analisis eksploratif (Exploratory Factor Analysis/EFA)

Pada EFA digunakan untuk pengembangan teori atau konsep sebuah variabel. Tujuan dari analisis eksploratif adalah untuk menemukan konstruksi dasar yang mempengaruhi sekumpulan respon.

Kegunaan dalam analisis eksploratif yaitu:

a. Menentukan kelompok-kelompok dari kuesioner yang saling bergantung.

b. Menentukan features yang paling penting dalam mengklasifikasikan bagian dari suatu kelompok.

c. Mengidentifikasi suatu konstruksi berdasarkan respon pada suatu area tertentu.

d. Membangkitkan factor score yang mengarah besaran pada konstruksi dasar untuk dipakai dalam analisis lainnya.

e. Mendemonstrasikan dimensi-dimensi pada suatu skala pengukuran.

2. Analisis konfirmatif (Confirmatory Factor Analysis/CFA)

Pada CFA digunakan untuk menguji atau mengkonfirmasi teori dalam sebuah model. Tujuan dari analisis komfirmatif adalah menentukan kemampuan dari sebuah model 
faktor awal yang digunakan untuk menduga sekumpulan data yang diamati.

Kegunaan dalam analisis konfirmatif yaitu:

a. Melakukan perbandingan dari kemampuan dua model yang berbeda dengan menggunakan sekelompok data yang sama.

b. Mengetahui validitas pada suatu model faktor tunggal.

c. Menguji kaitan antara dua atau lebih factor loading.

d. Menguji signifikansi dari factor loading tertentu.

\section{METODE PENELITIAN}

Data yang digunakan dalam penelitian ini adalah data primer dengan menyebar kuesioner kepada pelanggan sepeda motor matic Honda di Kota Denpasar.

Jenis pengambilan sampel yang digunakan dengan menggunakan teknik Accidental sampling dan Purposive sampling. Accidental sampling merupakan teknik penentuan sampel berdasarkan faktor spontanitas, artinya siapa saja yang secara tidak sengaja bertemu dengan peneliti dan sesuai dengan karakteristiknya, maka orang tersebut dapat digunakan sebagai sampel atau responden (Jhonson \& Wichern [4]). Sedangkan Purposive sampling adalah suatu teknik memilih objek terseleksi berdasarkan ciri-ciri khusus yang dimiliki sampel tersebut yang dipandang mempunyai hubungan erat dengan populasi yang diteliti. Ciri-ciri khusus yang terdapat dalam penelitian ini adalah orang yang berumur 17th keatas, memiliki dan menggunakan motor matic Honda lebih dari 1 tahun, dan pernah mencoba motor matic lainnya. Jumlah sampel yang digunakan dalam penelitian ini 150 responden.

Pengujian instrumen terdiri dari uji validitas dan uji reliabilitas. Uji tersebut digunakan untuk mengetahui valid dan reliabel atau tidaknya kuesioner yang digunakan. Rumus dari uji validitas sebagai berikut:

$r_{x y}=\frac{\sum x y-\left(\sum x\right)\left(\sum y\right) / n}{\sqrt{\left[\sum x^{2}-\left(\sum x\right)^{2} / n\right]\left[\sum y^{2}-(\Sigma y)^{2} / n\right]}}$
Sedangkan rumus uji reliabilitas sebagai berikut:

$\alpha=\frac{k}{k-1}\left(1-\frac{\Sigma \sigma_{i}^{2}}{\sigma_{t}^{2}}\right)$

Indikator penelitian yang terdapat dalam penelitian ini disajikan dalam tabel berikut:

Tabel 2. Identifikasi Indikator Penelitian

\begin{tabular}{|c|c|c|}
\hline Faktor & Dimensi & Indikator \\
\hline \multirow[t]{14}{*}{$\begin{array}{l}\text { Kualitas } \\
\text { Produk }\end{array}$} & \multirow[t]{3}{*}{ Performance } & $\begin{array}{l}\text { Menghemat bahan } \\
\text { bakar }\end{array}$ \\
\hline & & Akselerasi \\
\hline & & Kenyamanan \\
\hline & \multirow[t]{2}{*}{ Reliability } & $\begin{array}{l}\text { Motor tidak rusak } \\
\text { parah. }\end{array}$ \\
\hline & & Jarang ke bengkel. \\
\hline & \multirow[t]{3}{*}{ Fitur } & $\begin{array}{l}\text { Dilengkapi standar } \\
\text { samping otomatis. }\end{array}$ \\
\hline & & $\begin{array}{l}\text { Dilengkapi brake } \\
\text { lock }\end{array}$ \\
\hline & & Dilengkapi bagasi \\
\hline & \multirow[t]{2}{*}{ Durability } & Jangka waktu \\
\hline & & Lama atau umur aki \\
\hline & Conformance & Kesesuaian produk \\
\hline & \multirow[t]{3}{*}{ Design } & $\begin{array}{l}\text { Fostur body yang } \\
\text { kuat. }\end{array}$ \\
\hline & & Warna \\
\hline & & Striping \\
\hline Harga & & Harga terjangkau \\
\hline \multirow{5}{*}{$\begin{array}{l}\text { Service } \\
\text { Quality }\end{array}$} & & Harga bersaing \\
\hline & \multirow[t]{3}{*}{$\begin{array}{l}\text { Assurance } \\
\text { Tangible }\end{array}$} & $\begin{array}{l}\text { Sesuai dengan } \\
\text { kualitas }\end{array}$ \\
\hline & & Penampilan fisik \\
\hline & & Peralatan bengkel \\
\hline & Emphaty & Onderdil \\
\hline \multirow[t]{5}{*}{$\begin{array}{l}\text { Emotional } \\
\text { Factor }\end{array}$} & \multirow[t]{3}{*}{ Reliability } & $\begin{array}{l}\text { Kehandalan } \\
\text { melayani pelanggan }\end{array}$ \\
\hline & & Model yang trendy \\
\hline & & Iklan yang menarik \\
\hline & $\begin{array}{l}\text { Self } \\
\text { Expressive } \\
\text { Value }\end{array}$ & $\begin{array}{l}\text { Pertimbangan dari } \\
\text { lingkungan sekitar }\end{array}$ \\
\hline & $\begin{array}{l}\text { Brand } \\
\text { Personality }\end{array}$ & $\begin{array}{l}\text { Pandangan dari diri } \\
\text { sendiri }\end{array}$ \\
\hline \multirow[t]{2}{*}{ Kemudahan } & & $\begin{array}{l}\text { kemudahan } \\
\text { mendapatkan } \\
\text { produk } \\
\end{array}$ \\
\hline & & $\begin{array}{l}\text { Kemudahan } \\
\text { mendapatkan suku } \\
\text { cadang }\end{array}$ \\
\hline
\end{tabular}

Langkah-langkah yang digunakan menganalisis data dalam penelitian ini yaitu:

1. Menganalisis secara deskriptif terhadap variabel-variabel karakteristik tersebut. 
2. Menguji validitas dan reliabilitas data pada 30 kuesioner.

3. Menguji variabel-variabel yang ditentukan dengan metode Bartlett Test of Sphericity, KMO (Kaiser Mayer Olkin), dan MSA (measure of sampling adequacy). Ukuran KMO yang disarankan paling tidak diatas 0,80 . Tetapi dari 0,5 biasanya masih bisa diakomodasi untuk penentuan analisis faktor (Widarjono [5]).

4. Menentukan ragam dari masing-masing variabel.

5. Menentukan jumlah indikator berdasarkan masing-masing dimensi dari setiap faktor.

6. Menentukan nilai komponen matrik dari masing-masing dimensi setiap faktor.

7. Melakukan interpretasi faktor.

8. Mengetahui faktor dominan yang berpengaruh terhadap loyalitas pelanggan motor matic honda dilihat dari faktor yang memiliki nilai eigen tertinggi.

9. Menentukan strategi pemasaran yang efektif terhadap produk sepeda motor matic Honda dengan melihat nilai eigen, nilai komunalitas, nilai komponen matrik yang tertinggi dan terendah dari dimensi masingmasing faktor.

10. Kesimpulan hasil yang didapatkan.

\section{HASIL DAN PEMBAHASAN}

Hasil deskritif dari penelitian ini didapatkan bahwa tipe motor matic Honda yang mendomisili yaitu vario memiliki persentase 76\%. Hal ini dikarenakan image dari sepeda motor matic Honda yaitu vario dimana tipe vario merupakan sepeda motor matic Honda yang paling pertama muncul.

Uji validitas dan reliabilitas yang didapatkan pada 30 responden yang dilakukan pada setiap faktor menyatakan bahwa validitas sudah memenuhi syarat,dimana korelasi dari setiap item pernyataan memiliki nilai lebih dari sama dengan 0,3 [6]. Tetapi ada satu item pernyataan yang memiliki nilai korelasi dibawah 0,3 dipertahankan karena analisis tidak mengalami peningkatan nilai alpha cronbach dari 0,854 akan tetap bernilai 0,854 dan memiliki tanda yang sama positif dengan korelasi lainnya.Sedangkan reliabilitas dari setiap item pernyataan dan setiap faktor memiliki nilai lebih besar sama dengan 0.5 (Sugiyono [7]).

Nilai eigen yang tertinggi merupakan faktor yang menjadi dominan yang berpengaruh terhadap loyalitas sepeda motor matic Honda di Kota Denpasar.Hasil dari analisis faktor yang mempunyai nilai eigen lebih dari satu yaitu 5 faktor diantaranya kualitas produk $(2,302)$, harga $(1,446)$, kualitas pelayanan $(1,577)$, emotional faktor (3,365), dan kemudahan (1,561). Sehingga, nilai eigen yang tertinggi yaitu emotional factor. Nilai eigen emotional factor tersebut dapat dilihat pada tabel berikut:

Tabel 2. Nilai Eigen dari Emotional Factor

\begin{tabular}{crr}
\multicolumn{3}{c}{ Extraction Sums of Squared Loadings } \\
\hline Total & \% of Variance & Cumulative \% \\
\hline 3,365 & 48,078 & 48,078 \\
\hline
\end{tabular}

Penentuan strategi pemasaran yang efektif dilihat dari dimensi setiap faktor yang memiliki nilai eigen, nilai komunalitas tertinggi dan terendah. Analisis menyatakan bahwa strategi pemasaran akan dijelaskan berdasarkan lima faktor sebagai berikut:

1. Kualitas Produk

Nilai eigen yang tertinggi dari faktor kualitas produk adalah dimensi design sebesar 2,255 dengan varian $56,377 \%$. Nilai komunalitas tertinggi $67,2 \%$ dan nilai komponen matrik 0,820 merupakan strategi pemasaran yang sangat dilihat dalam produk sepeda motor matic Honda di Kota Denpasar yaitu $\mathrm{X}_{17}$ dengan melihat striping (stiker) sepeda motor matic Honda yang dibuat menarik. Sedangkan nilai eigen yang terendah dimensi fitur dengan nilai komunalitas sebesar $63,6 \%$ dan nilai komponen matrik 0,798 . Sehingga, strategi pemasaran yang tidak dilihat adalah $\mathrm{X}_{7}$ (motor matic Honda dilengkapi brake lock berfungsi untuk mencegah motor loncat saat dinyalakan) dan $\mathrm{X}_{8}$ (motor matic Honda dilengkapi dengan bagasi yang luas).

2. Harga

Faktor harga tidak terbagi oleh dimensi, sehingga strategi pemasaran yang dilihat oleh 
masyarakat di Kota Denpasar adalah $\mathrm{X}_{18}$ dengan pernyataan harga motor matic Honda terjangkau dan $\mathrm{X}_{19}$ dengan pernyataan harga motor matic Honda dapat bersaing dengan merk lainnya. Nilai eigen yang terbentuk 1,446 yang mewakili kumulatif 48,200\% dengan nilai komunalitas $71,2 \%$ dan nilai komponen matrik 0,844 .

3. Kualitas Pelayanan

Strategi pemasaran yang dilihat dalam faktor kualitas pelayanan adalah dimensi reliability yang nilai eigen 2,170 dengan komponen pembentuk $72,328 \%$, nilai komunalitas tertinggi $78,2 \%$, nilai komponen matrik sebesar 0,884 adalah $\mathrm{X}_{24}$ dengan pernyataan karyawan Honda memberikan pelayanan yang jujur. Sedangkan strategi pemasaran sangat tidak dilihat oleh pelanggan adalah dimensi responsiveness $(1,583)$ dengan nilai komunalitas $(79,2 \%)$ dan nilai komponen matrik $(0,890)$ adalah $\mathrm{X}_{26}$ dan $\mathrm{X}_{27}$. Hal ini berarti karyawan Honda menanggapi keluhan pelanggan dengan memberikan informasi yang jelas dan karyawan Honda memberikan informasi yang dapat dipercaya tentang sepeda motor matic Honda tidak diperhatikan oleh masyarakat di Kota Denpasar.

\section{Emotional Factor}

Emotional factor dibagi menjadi tiga dimensi. Dimana dimensi yang memiliki nilai eigen tertinggi $(1,956)$ adalah dimensi estetika dengan variabel $\mathrm{X}_{34}$ dengan nilai komunalitas tertinggi $80,8 \%$ dan nilai komponen matrik 0,899 . Sedangkan nilai eigen terendah 1,440 adalah dimensi self expressive value dengan memiliki nilai komunalitas $72,0 \%$ dan nilai komponen matrik 0,848 yaitu variabel $\mathrm{X}_{36}, \mathrm{X}_{37}$. Dapat disimpulkan bahwa strategi pemasaran yang dilihat dari emotional factor adalah daya tarik model motor matic Honda yang trendy membuat pelanggan tertarik untuk membelinya.

\section{Kemudahan}

Strategi pemasaran dalam faktor kemudahan tidak diketahui dari dimensi lagi tetapi langsung dari indikatornya. Faktor kemudahan memiliki nilai eigen 1,561 dengan nilai komunalitas $78,1 \%$ dan nilai komponen matrik 0,884. Sehingga strategi pemasaran yang dilihat yaitu $\mathrm{X}_{40}$ dengan pernyataan tipe motor matic Honda mudah didapatkan dan $\mathrm{X}_{41}$ dengan pernyataan suku cadang Honda ada dimana-mana sehingga mudah dicari.

\section{KESIMPULAN}

Berdasarkan hasil dan pembahasan di atas maka dapat ditarik kesimpulan sebagai berikut:

1. Faktor dominan yang berpengaruh terhadap loyalitas sepeda motor matic Honda yaitu emotional factor dengan memperoleh nilai eigen sebesar 3,365.

2. Strategi pemasaran yang efektif terhadap produk sepeda motor matic Honda dilihat dari nilai eigen tertinggi dari dimensi masing-masing faktor yaitu sebagai berikut:

(a) Dimensi yang menjadi strategi pemasaran efektif dari faktor kualitas produk adalah dimensi design dengan melihat striping (stiker) motor matic Honda dibuat menarik.

(b) Strategi pemasaran yang dilihat dalam produk sepeda motor matic Honda di Kota Denpasar dari faktor harga yaitu harga motor matic Honda terjangkau dan harga motor matic Honda dapat bersaing dengan merk lainnya.

(c) Dimensi dari faktor kualitas pelayanan yang menjadi strategi pemasaran efektif adalah dimensi reliability dengan melihat karyawan Honda memberikan pelayanan yang jujur.

(d) Dimensi estetika dari emotional factor merupakan strategi pemasaran yang efektif dari segi daya tarik model motor matic Honda yang trendy membuat pelanggan berminat untuk membeli.

(e) Dalam faktor kemudahan yang dilihat untuk menjadi strategi pemasaran yang efektif yaitu tipe motor matic Honda mudah didapatkan dan suku cadang Honda ada dimana-mana sehingga mudah dicari. 


\section{DAFTAR PUSTAKA}

[1] Kotler, Philip. 2004. Manajemen Pemasaran Edisi Millenium. Jakarta: PT. Prenhallinda.

[2] Irawan, H. 2002. 10 Prinsip Kepuasan Pelanggan. Jakarta: PT. Elex Media Komputindo.

[3] Sarwono, Jonathan. 2005. Teori dan Praktik Riset Pemasaran dengan SPSS. Yogyakarta: Penerbit ANDI.

[4] Jhonson, Richard A. and Wichern, Dean W. 1998. Applied Multivariate Statistical Analisis. $6^{\text {th }}$ ed. New Jersey: Pearson International Edition.

[5] Widarjono, Agus. 2010. Analisis Statistika Multivariate Terapan. Yogyakarta: Penerbit Sekolah Tinggi Ilmu Manajemen YKPN.

[6] Brown, Emma and Chen, Huey-Shys. 2010.HIV-RelatedScales Psychometrically Validated for Rulal African-American Women. Journal of Nursing Research. Vol. 10, No. 4.

[7] Sugiyono. 2008. Metode Penelitian Kuantitatif, Kualitatif dan $R \quad \& \quad D$. Bandung: Penerbit Alfabeta. 